\title{
Extension of Axiomatic Design Method for Fuzzy Linguistic Multiple Criteria Group Decision Making with Incomplete Weight Information
}

\author{
Ming Li \\ School of Business Administration, China University of Petroleum, Beijing 102249, China \\ Correspondence should be addressed to Ming Li, limingzyq@gmail.com
}

Received 20 September 2012; Accepted 9 November 2012

Academic Editor: J. J. Judice

Copyright (C) 2012 Ming Li. This is an open access article distributed under the Creative Commons Attribution License, which permits unrestricted use, distribution, and reproduction in any medium, provided the original work is properly cited.

\begin{abstract}
Axiomatic design (AD) provides a framework to describe design objects and a set of axioms to evaluate relations between intended functions and means by which they are achieved. It has been extended to evaluate alternatives in engineering under fuzzy environment. With respect to multiple criteria group decision making (MCDM) with incomplete weight information under fuzzy linguistic environment, a new method is proposed. In the method, the fuzzy axiomatic design based on triangle representation model is used to aggregate the linguistic evaluating information. In order to get the weight vector of the criteria, we establish a nonlinear optimization model based on the basic ideal of fuzzy axiomatic design (FAD), by which the criteria weights can be determined. It is based on the concept that the optimal alternative should have the least weighted information content. Then, the weighted information content is derived by summing weighted information content for each criterion. The alternative that has the least total weighted information content is the best. Finally, a numerical example is used to illustrate the availability of the proposed method.
\end{abstract}

\section{Introduction}

The increasing complexity of the socio-economic environment makes multiple criteria decision-making (MCDM) problems widespread in engineering decision making. For example, MCDM has been used in industrial engineering and manufacturing systems [15], aerospace mechanical engineering [6], bioengineering [7], computer engineering [8-11], chemical engineering $[12,13]$, and construction engineering [14]. MCDM refers to making preference decisions over the available alternatives that are characterized by multiple criteria [15]. Decision makers give opinions for each criterion of alternatives with quantitative and qualitative terms. In decision-making process, the exact preference information is better than 
inexact preference information about the alternatives with respect to a criterion. In addition to the precision decision-making problems, in reality, decision makers often face vague and fuzzy decision-making problems. Many aspects in the real world cannot be assessed in a quantitative form but rather in a qualitative way, that is, with vague or imprecise knowledge. For example, when classifying the documents, linguistic labels like "high", "medium", and "low" are used to judge the document relevance [8]. Since making decisions with linguistic information is a usual task faced by many decision makers, approaches have been proposed for dealing with the linguistic information [16, 17]. Fuzzy set theory (FST) is a methodology for representing and manipulating the fuzzy data instead of precise data. It is an extension of ordinary set theory for dealing with uncertainty and imprecision associated within formation. The theory of fuzzy logic provides a mathematical strength to capture the uncertainties associated with human cognitive process, such as thinking and reasoning [16].

The classical MCDM methods cannot effectively handle problems with fuzzy information. Hence, fuzzy multiple criteria decision making (FMADM) has attracted great interest of the researchers [18-27]. Many classical MCDM methods are extended under fuzzy environment and used for various problems. For example, Chen [28] extended the TOPSIS in the fuzzy environment. In the proposed fuzzy TOPSIS method, the rating of each alternative and the weight of each criterion are described by linguistic terms which are expressed in triangular fuzzy numbers. The fuzzy VIKOR method [29] has been developed to solve fuzzy multicriteria problem with conflicting and noncommensurable (different units) criteria. Opricovic [30] used the fuzzy VIKOR to plan water resources. Chang [31] proposed a new approach for handling fuzzy AHP, with the use of triangular fuzzy numbers for pairwise comparison scale of fuzzy AHP and the use of the extent analysis method for the synthetic extent value of the pairwise comparison. Goumas and Lygerou [32] made an extension of the PROMETHEE method for decision making in fuzzy environment. In the study, the proposed method is applied for the evaluation and ranking of alternative energy exploitation schemes of a low-temperature geothermal field. Chen et al. [33] proposed an approach to evaluate restoration plans for power distribution systems based on the hybrid fuzzy grey relational model.

AD principles were initiated by Suh and Sekimoto [34] and are wildly used in engineering [34-42]. The ultimate goal is to establish a scientific basis for designing to improve design activities by providing the designer with a theoretical foundation based on logical and rational thought process and tools [35]. AD principles allow for the selection of not only the best alternative within a set of criteria but also the most appropriate alternative. It is the main difference between the classical MCDM method and AD. Recently, the MCDM methods based on AD principles are proposed and widely used in engineering. For example, Babic [36] developed a method based on AD principles. The method assists the designers in determining the appropriate flexible manufacturing system configuration at the design stage. Kulak [37] developed a decision support system called FUMAHES based on information axiom of the design principles to handle equipment selection problem. Kulak and Kahraman [38] proposed the new MCDM method based on information axiom under fuzzy environment. The evaluation of the alternatives and the definition of functional requirements were defined by triangular fuzzy numbers. The proposed approach was applied to multicriteria comparison of advanced manufacturing systems. Kulak and Kahraman [39] applied the information axiom to a multicriteria transportation company selection problem. Kulak et al. [40] developed weighted information axiom approach for the multiattribute decision problems for the first time. The proposed approach integrated with 
the unweighted information axiom was used to select the punching machines. GonçalvesCoelho and Mourão [41] used axiomatic design principles to select the manufacturing technologies. The axiom was used to check whether the design parameters satisfied the functional requirements. Subsequently, the information axiom was employed to select the most appropriate technology. Celik et al. [42] used the fuzzy information axiom to select the best alternatives among shipyards. The information axiom allows decision makers to define the design interval for each criterion.

Although the axiomatic design has been extended to solve the group decision-making problems under fuzzy environment in which both the criteria values and criteria weights take the form of fuzzy linguistic information, it fails to solve the group decision-making problems with linguistic evaluation information in which criteria weights are incompletely known. In this paper, a new method for fuzzy linguistic multiple criteria group decision-making problem with incomplete weight information based on the traditional ideas of axiomatic design is developed. The remainder of this paper is set out as follows. In the next section, we introduce some basic concepts of axiomatic design and fuzzy set theory. In the third section, we develop a practical method based on the traditional ideas of axiomatic design for linguistic group decision-making problem with incomplete weight information. In Section 4, we give an illustrative example to illustrate the availability of the proposed model. In the final section, we conclude the paper.

\section{Preliminaries}

\subsection{Axiomatic Design}

Axiomatic design (AD) is a scientific and systematic basis that provides structure to design process for engineers. The most important concepts in axiomatic design are the design axioms, which are independence axiom and information axiom. The details of the two design axioms are described as follows [34-42].

\subsubsection{Independence Axiom}

It means that the independence of functional requirements (FRs) must always be maintained, where FRs are defined as the minimum set of independent requirements that characterize the design goals. Moreover, it states that, in an acceptable design, the design parameters (DPs) can be adjusted to satisfy its corresponding FR without affecting other FRs.

\subsubsection{Information Axiom}

The best design is a functionally uncoupled design that has the minimum information content. In other words, among those designs that satisfy the independence axiom, the best design is the design that has the smallest information content.

The information axiom is a conventional method and facilitates the selection of proper alternative. It is symbolized by the information content that is related to the probability of satisfying the design goals. The information content $(I)$ is given by

$$
I_{i}=\log _{2} \frac{1}{p_{i}}
$$

where $p_{i}$ is the probability of achieving a given FR. 
If there is more than one FR, information content is the sum of all these probabilities, which is calculated as

$$
I_{\text {system }}=-\log _{2}\left(\prod_{i=1}^{m} p_{i}\right)=-\sum_{i=1}^{m} \log _{2} p_{i}=-\sum_{i=1}^{m} \log _{2} \frac{1}{p_{i}} .
$$

In design situation, the probability of success is given by what the designer wishes to achieve in terms of tolerance (i.e., design range) and what the system is capable of delivering (i.e., system range). The overlap between the design range and the system range is the region where the acceptable solution exists. Therefore, in the case of uniform probability distribution function $p_{i}$ may be written as

$$
p_{i}=\frac{\text { Common Area }}{\text { System Design }} \text {. }
$$

Therefore, the information content is equal to

$$
I_{i}=\log _{2} \frac{\text { System Design }}{\text { Common Area }}
$$

In order to deal with linguistic information, the information axiom is extended under fuzzy environment and is used as a new methodology for multiple criteria decision making under fuzzy environment [38]. Triangular fuzzy numbers (TFNs) are used to depict the design goal and properties of the alternatives. The common area is the intersection area of the system's TFN and the design's TFN (Figure 1). Therefore, information content under fuzzy environment is calculated by

$$
I=\log _{2} \frac{\text { TFN of System Design }}{\text { Common Area }}
$$

\subsection{Fuzzy Set Theory}

In most decision-making problems, decision maker often provides his evaluation information in a linguistic form. For example, when evaluating airline safety, linguistic labels like "high", "medium", and "low" are used [43]. Fuzzy set theory is a commonly used method to deal with the linguistic information. It is possible to use different fuzzy numbers depending on the situation. Since triangular fuzzy numbers are computational simplicity and are the effective way to formulate decision problems in linguistic environment [44], they are adopted in the study. The preliminary of fuzzy set theory is given as follows [16].

Definition 2.1. A fuzzy set $\widetilde{A}$ in a universe of discourse $X$ is characterized by a membership function $\mu_{\tilde{A}}(x)$ which associates with each element $x$ in $X$ a real number in the interval $[0,1]$. The function value $\mu_{\tilde{A}}(x)$ is termed the grade of membership of $x$ in $\tilde{A}$. 


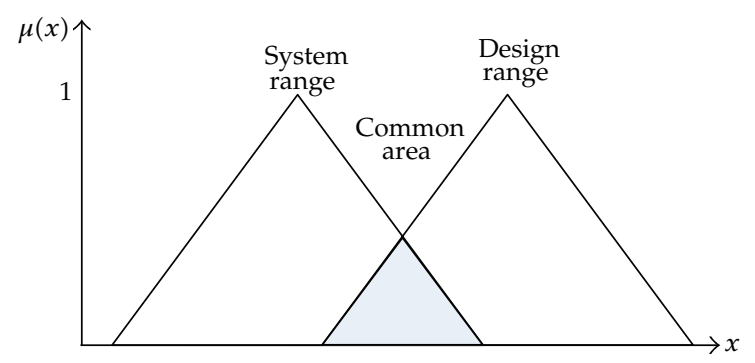

Figure 1: The common area of system and design ranges.

Definition 2.2. A triangular fuzzy number $\tilde{a}$ can be defined by a triplet $\left(a_{1}, a_{2}, a_{3}\right)$ as shown in Figure 2. The membership function $\mu_{\tilde{a}}(x)$ is defined as follows:

$$
\mu_{\tilde{a}}(x)= \begin{cases}0, & x<a_{1}, x>a_{3} \\ \frac{x-a_{1}}{a_{2}-a_{1}}, & a_{1} \leq x \leq a_{2} \\ \frac{x-a_{3}}{a_{3}-a_{2}}, & a_{2} \leq x \leq a_{3} .\end{cases}
$$

Definition 2.3 (arithmetic operations on fuzzy numbers). While there are various operations of triangular fuzzy numbers, only the main operations used in this study are illustrated. If we define two positive triangular fuzzy numbers $\tilde{a}=\left(a_{1}, a_{2}, a_{3}\right)$ and $\tilde{b}=\left(b_{1}, b_{2}, b_{3}\right)$, then

$$
\begin{gathered}
\tilde{a}+\tilde{b}=\left(a_{1}, a_{2}, a_{3}\right)+\left(b_{1}, b_{2}, b_{3}\right)=\left(a_{1}+b_{1}, a_{2}+b_{2}, a_{3}+b_{3}\right), \\
\tilde{a}-\tilde{b}=\left(a_{1}, a_{2}, a_{3}\right)-\left(b_{1}, b_{2}, b_{3}\right)=\left(a_{1}-b_{1}, a_{2}-b_{2}, a_{3}-b_{3}\right), \\
\tilde{a} \times \tilde{b}=\left(a_{1}, a_{2}, a_{3}\right) \times\left(b_{1}, b_{2}, b_{3}\right)=\left(a_{1} \times b_{1}, a_{2} \times b_{2}, a_{3} \times b_{3}\right), \\
\frac{\tilde{a}}{\tilde{b}}=\frac{\left(a_{1}, a_{2}, a_{3}\right)}{\left(b_{1}, b_{2}, b_{3}\right)}=\left(\frac{a_{1}}{b_{1}}, \frac{a_{2}}{b_{2}}, \frac{a_{3}}{b_{3}}\right), \\
\tilde{a} * K=\left(k a_{1}, k a_{2}, k a_{3}\right) .
\end{gathered}
$$

\section{The Axiomatic Design Method for Linguistic Group Decision-Making Problems with Incomplete Weight Information}

In this study, both ratings of alternatives and functional requirements (FRs) are evaluated by each expert. Therefore, a group decision-making method needs aggregating of experts' opinions and taking functional requirements into consideration [45]. In the following, the steps of the method are presented.

Let $A=\left\{A_{1}, A_{2}, \ldots, A_{m}\right\}$ be a discrete set of alternatives, $C=\left\{C_{1}, C_{2}, \ldots, C_{n}\right\}$ the set of criteria, and $D=\left\{D_{1}, D_{2}, \ldots, D_{t}\right\}$ the set of decision makers, and assume that the degree of importance of expert $D_{i}$ is $\eta_{i}$, where $\eta_{i} \in[0,1]$ and $\sum_{v=1}^{t} \eta_{v}=1$. Suppose that $\widetilde{R}_{k}=\widetilde{r}_{i j}^{(k)}$ is 


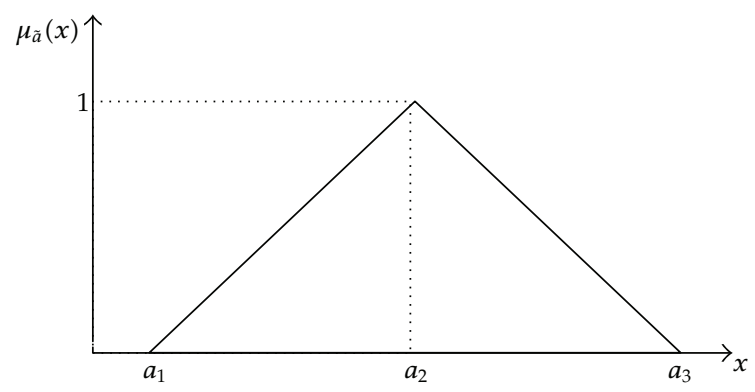

Figure 2: Triangular fuzzy number.

the group decision-making matrix, where $\tilde{x}_{i j}^{(k)} \in S$ is a preference values, which take the form of triangular fuzzy number, given by the decision maker $D_{k} \in D$, for the alternative $A_{i} \in A$, with respect to the criterion $C_{j} \in C$. Let $F=\left\{\widehat{f}_{1}, \widehat{f}_{2}, \ldots, \widehat{f}_{n}\right\}$ be a set of functional requirements (FRs), that is, the set of goals for the criteria, where $\widehat{f}_{j} \in F$ take the form of triangular fuzzy number. The decision makers use the fuzzy linguistic terms to express their preferences. The fuzzy linguistic terms and their corresponding values are shown in Table 1.

The information about criteria weights is incompletely known. Let $w=\left\{w_{1}, w_{2}\right.$, $\left.\ldots, w_{n}\right\} \in H$ be the weight vector of criteria, where $w_{j} \geq 0, j=1,2, \ldots, n, \sum_{j=1}^{n} w_{j}=1, H$ is a set of the known weight information, which can be constructed by the following forms [45-49], for $j \neq i$.

Form 1. A weak ranking: $w_{i} \geq w_{j}$.

Form 2. A strict ranking: $w_{i}-w_{j} \geq \alpha_{i}, \alpha_{i}>0$.

Form 3. A ranking of differences: $w_{i}-w_{j} \geq w_{k}-w_{l}$, for $j \neq l \neq k$.

Form 4. A ranking with multiples: $w_{i} \geq \beta_{j} w_{j}, 0 \leq \beta_{j} \leq 1$.

Form 5. An interval form: $\alpha_{i} \leq w_{i} \leq \alpha_{i}+\varepsilon_{i}, 0 \leq \alpha_{i} \leq \alpha_{i}+\varepsilon_{i} \leq 1$.

Axiomatic design method with incomplete linguistic weight information has the following steps.

Step 1. Transform the data into triangular fuzzy numbers. Preference values and functional requirements take the form of triangular fuzzy number in decision making. Since linguistic terms are not mathematically operable, they must be transformed to numbers. They can be transformed to fuzzy numbers in Table 1.

Step 2. Aggregate the experts' opinions. Since the aggregation method of expert opinions presented by Chen is more efficient in calculating the degree of similarity between the subjective estimates of experts, it is adopted in the study [45]. The steps of the method are as follows. 
Table 1: Linguistic values for rating of criteria and grade of importance.

\begin{tabular}{lc}
\hline Linguistic values & Fuzzy number \\
\hline Definitely low (DL) & $(0,0,0.2)$ \\
Very low (VL) & $(0.05,0.2,0.35)$ \\
Low (L) & $(0.2,0.35,0.5)$ \\
Middle (M) & $(0.35,0.5,0.65)$ \\
High (H) & $(0.5,0.65,0.8)$ \\
Very high (VH) & $(0.65,0.8,0.95)$ \\
Definitely high $(\mathrm{DH})$ & $(0.8,1,1)$ \\
\hline
\end{tabular}

Step 2.1. Calculate the degree of agreement. Based on (3.1), calculate the degree of agreement $S\left(\widehat{R}_{i}, \widehat{R}_{j}\right)$ of the opinions between each pair of experts $D_{i}$ and $D_{j}$, where $S\left(\widehat{R}_{i}, \widehat{R}_{j}\right) \in[0,1]$, $1 \leq i \leq n, 1 \leq j \leq n, i \neq j$ as follows:

$$
S\left(\widehat{R}_{p}, \widehat{R}_{q}\right)=\frac{1}{m \times n} \sum_{i=1}^{m} \sum_{j=1}^{n}\left(1-\frac{\left|\widehat{r}_{i j 1}^{(p)}-\widehat{r}_{i j 1}^{(q)}\right|+\left|\widehat{r}_{i j 2}^{(p)}-\widehat{r}_{i j 2}^{(q)}\right|+\left|\widehat{r}_{i j 3}^{(p)}-\widehat{r}_{i j 3}^{(q)}\right|}{3}\right) .
$$

Step 2.2. Calculate the average degree of agreement $A\left(E_{i}\right)$ of expert $D_{i}$, where

$$
A\left(E_{i}\right)=\frac{1}{n-1} \sum_{j=1, j \neq i}^{n} S\left(\widehat{R}_{i}, \widehat{R}_{j}\right) .
$$

Step 2.3. Calculate the relative degree of agreement $R A\left(E_{i}\right)$ of expert $D_{i}$, where

$$
R A\left(E_{i}\right)=\frac{A\left(E_{i}\right)}{\sum_{i=1}^{n} A\left(E_{i}\right)} .
$$

Step 2.4. Assume that the weight of the degrees of importance of the experts and the weight of the relative degree of agreement of the experts are $y_{1}$ and $y_{2}$, respectively, where $y_{1} \in[0,1]$ and $y_{2} \in[0,1]$. Calculate the consensus degree coefficient $C\left(E_{i}\right)$ of expert $D_{i}$, where

$$
C\left(E_{i}\right)=\frac{y_{1}}{y_{1}+y_{2}} * w_{i}+\frac{y_{1}}{y_{1}+y_{2}} * R A\left(E_{i}\right)
$$

Step 2.5. The aggregation result of the fuzzy opinions is $\widetilde{R}$, where

$$
\begin{aligned}
& \tilde{R}=C\left(E_{1}\right) \otimes R_{1} \oplus C\left(E_{2}\right) \otimes R_{2} \cdots C\left(E_{n}\right) \otimes R_{n}, \\
& \tilde{R}=C\left(E_{1}\right) \otimes R_{1} \oplus C\left(E_{2}\right) \otimes R_{2} \cdots C\left(E_{n}\right) \otimes R_{n},
\end{aligned}
$$

where operators $\otimes$ and $\oplus$ are the fuzzy multiplication operator and the fuzzy addition operator, respectively. 
Step 3. Calculate the information content. For each $F R_{i}$ the information content is calculated by

$$
I_{i j}= \begin{cases}0 & \text { if } \widehat{r}_{i j 1}>\widehat{f}_{j 3} \text { or } \widehat{r}_{i j 3}<\widehat{f}_{j 1}, \\ \log _{2} \frac{\text { TFN System Design of } \widehat{f}_{j}}{\text { Common Area of } \widehat{r}_{i j} \text { and } \widehat{f}_{j}} & \text { if } \widehat{r}_{i j 1} \leq \widehat{f}_{j 3}, \widehat{r}_{i j 3} \geq \widehat{f}_{j 1},\end{cases}
$$

where $\widehat{r}_{i j 1}$ and $\widehat{f}_{j 3}$ are the lower and upper values of the alternative $A_{i}$ under the criterion $C_{i}$, respectively, and $\widehat{f}_{j 1}$ and $\widehat{f}_{j 3}$ are the lower and upper values of $F R_{i}$.

Step 4. Calculate the weighted information content. The information content of $i$ th alternative on $i$ th criterion can be got as follows:

$$
I_{i j}^{w}=\frac{1}{w_{j}} \times I_{i j}
$$

where $I_{i}^{w}$ is the weighted information content of $i$ th alternative, $I_{i j}$ is the information content of $i$ th alternative on $i$ th criterion, and $w_{j}$ is the weight of $i$ th criterion.

Note that since the alternative is better with less information content, the weight $w_{j}$ is not used directly but is transformed to a decreasing function as in the equation. Then with a larger weight of the criterion, the information contents decrease further and the corresponding alternative gets a higher priority.

Since we need the overall performance of the alternative on each criterion, the weighted average method is used and the total weighted information content of the alternative is the sum of all the weighted information content of the alternative on each criterion. Then the total weighted information content can be got as follows:

$$
I_{i}^{w}=\sum_{j=1}^{n} I_{i j}^{w}=\sum_{j=1}^{n} \frac{1}{w_{j}} \times I_{i j},
$$

where $I_{i}^{w}$ is the weighted information content of $i$ th alternative, $I_{i j}$ is the information content of $i$ th alternative on $i$ th criterion, and $w_{j}$ is the weight of $i$ th criterion.

However, the information about criteria weights is incompletely known, and we should get criteria weights firstly. The alternative that has the minimum information content value is the best alternative for our goal, in order to get the weighted information content, we establish the following multiple objective optimization model M:

$$
\begin{aligned}
& \min \quad I=\sum_{i=1}^{m} I_{i}^{w}=\sum_{i=1}^{m} \sum_{j=1}^{n} \frac{1}{w_{j}} \times I_{i j}, \\
& \text { subject to: } \quad \omega \in H, \quad i=1,2, \ldots, m .
\end{aligned}
$$

By solving the model $\mathrm{M}$, we get the optimal solution $w=\left(w_{1}, w_{2}, \ldots, w_{n}\right)$, which can be used as the weight vector of criteria. Then the weighted information content of each alternative can be obtained with (3.8). 
Table 2: The evaluation information of KMSs given by the first respondent.

\begin{tabular}{cccccc}
\hline & $C_{1}$ & $C_{2}$ & $C_{3}$ & $C_{4}$ & $C_{5}$ \\
\hline$A_{1}$ & $\mathrm{H}$ & $\mathrm{H}$ & $\mathrm{H}$ & $\mathrm{VH}$ & $\mathrm{H}$ \\
$A_{2}$ & $\mathrm{VH}$ & $\mathrm{VH}$ & $\mathrm{VH}$ & $\mathrm{L}$ & $\mathrm{VH}$ \\
$A_{3}$ & $\mathrm{M}$ & $\mathrm{M}$ & $\mathrm{H}$ & $\mathrm{H}$ & $\mathrm{H}$ \\
$A_{4}$ & $\mathrm{H}$ & $\mathrm{H}$ & $\mathrm{M}$ & $\mathrm{M}$ & $\mathrm{H}$ \\
$A_{5}$ & $\mathrm{M}$ & $\mathrm{VH}$ & $\mathrm{M}$ & $\mathrm{L}$ & $\mathrm{VH}$ \\
$A_{6}$ & $\mathrm{M}$ & $\mathrm{H}$ & $\mathrm{L}$ & $\mathrm{VH}$ & $\mathrm{L}$ \\
\hline
\end{tabular}

Step 5. Select the best alternative. According to the information content value, the ranking order of all alternatives can be determined. If any alternative has the minimum information content value, then, it is the most desirable alternative.

\section{Illustrative Example}

In this section, we use an example of selecting the knowledge management system in computer software engineering to illustrate the proposed model. Knowledge management system (KMS) refers to the computer information systems employed to better retain, utilize, and share organizational knowledge. It is the key to implement knowledge management for organizations [50]. In order to find the most appropriate KMS, six knowledge management systems are to be evaluated. Let $A=\left\{A_{1}, A_{2}, A_{3}, A_{4}, A_{5}, A_{6}\right\}$ be the set of KMSs. We invited three respondents to participate in this study. Because of the different backgrounds of the respondents, their opinions are not treated equally. The weights of the respondents are 0.3, 0.3 , and 0.4 , respectively. The respondents must take a decision according to the five criteria including knowledge retrieval $\left(C_{1}\right)$, knowledge map $\left(C_{2}\right)$, access control $\left(C_{3}\right)$, expansion $\left(C_{4}\right)$, and integration $\left(C_{5}\right)$. These criteria are constructed from functional and performance aspects. The respondents use the terms in Table 1 to give their opinions. The linguistic evaluation information of knowledge management systems given by respondents is shown in Tables 2, 3, and 4. The functional requirements (FRs) of the criteria are shown in Table 5. Suppose that the degrees of importance of the experts and the weight of the relative degree of agreement of the experts are equal and the values are 0.5.

According to the judgment of the three respondents, the information about the criterion weights is partly known as follows:

$$
\begin{aligned}
& H=\left\{\begin{array}{l}
H \\
0.16 \leq w_{1} \leq 0.22,0.21 \leq w_{2} \leq 0.33,0.19 \leq w_{3} \leq 0.68,
\end{array}\right. \\
&\left.0.6 w_{3} \leq w_{4}, w_{1}-w_{5} \leq 0.06, w_{j} \geq 0, \sum_{j=1}^{5} w_{j}=1, j=1,2,3,4,5\right\} .
\end{aligned}
$$

Step 1. Transform the linguistic evaluation information and functional requirements into triangular fuzzy numbers. The transformed results are presented in Tables 6, 7, 8, and 9. 
Table 3: The evaluation information of KMSs given by the second respondent.

\begin{tabular}{lccccc}
\hline & $C_{1}$ & $C_{2}$ & $C_{3}$ & $C_{4}$ & $C_{5}$ \\
\hline$A_{1}$ & $\mathrm{H}$ & $\mathrm{M}$ & $\mathrm{VH}$ & $\mathrm{L}$ & $\mathrm{H}$ \\
$A_{2}$ & $\mathrm{VH}$ & $\mathrm{VH}$ & $\mathrm{M}$ & $\mathrm{VH}$ & $\mathrm{L}$ \\
$A_{3}$ & $\mathrm{M}$ & $\mathrm{L}$ & $\mathrm{M}$ & $\mathrm{H}$ \\
$A_{4}$ & $\mathrm{H}$ & $\mathrm{H}$ & $\mathrm{L}$ & $\mathrm{M}$ \\
$A_{5}$ & $\mathrm{M}$ & $\mathrm{MH}$ & $\mathrm{M}$ & $\mathrm{H}$ \\
$A_{6}$ & $\mathrm{M}$ & $\mathrm{M}$ & $\mathrm{VH}$ & $\mathrm{M}$ \\
\hline
\end{tabular}

Table 4: The evaluation information of KMSs given by the third respondent.

\begin{tabular}{llcccc}
\hline & $C_{1}$ & $C_{2}$ & $C_{3}$ & $C_{4}$ & $C_{5}$ \\
\hline$A_{1}$ & $\mathrm{M}$ & $\mathrm{H}$ & $\mathrm{VH}$ & $\mathrm{VL}$ & $\mathrm{H}$ \\
$A_{2}$ & $\mathrm{H}$ & $\mathrm{VH}$ & $\mathrm{M}$ & $\mathrm{L}$ & $\mathrm{H}$ \\
$A_{3}$ & $\mathrm{M}$ & $\mathrm{M}$ & $\mathrm{VH}$ & $\mathrm{M}$ & $\mathrm{M}$ \\
$A_{4}$ & $\mathrm{H}$ & $\mathrm{H}$ & $\mathrm{M}$ & $\mathrm{L}$ & $\mathrm{M}$ \\
$A_{5}$ & $\mathrm{H}$ & $\mathrm{VH}$ & $\mathrm{VH}$ & $\mathrm{H}$ & $\mathrm{VH}$ \\
$A_{6}$ & $\mathrm{M}$ & $\mathrm{M}$ & $\mathrm{L}$ & & \\
\hline
\end{tabular}

Step 2. Aggregate the respondents' opinions.

Step 2.1. Calculate the degree of agreement as follows:

$$
\begin{aligned}
& S\left(\widehat{R}_{1}, \widehat{R}_{2}\right)=\frac{1}{6 \times 5} \sum_{i=1}^{6} \sum_{j=1}^{5}\left(1-\frac{\left|\widehat{r}_{i j 1}^{(1)}-\widehat{r}_{i j 1}^{(2)}\right|+\left|\widehat{r}_{i j 2}^{(1)}-\widehat{r}_{i j 2}^{(q 2)}\right|+\left|\widehat{r}_{i j 3}^{(1)}-\widehat{r}_{i j 3}^{(2)}\right|}{3}\right)=0.8125, \\
& S\left(\widehat{R}_{1}, \widehat{R}_{3}\right)=\frac{1}{6 \times 5} \sum_{i=1}^{6} \sum_{j=1}^{5}\left(1-\frac{\left|\widehat{r}_{i j 1}^{(1)}-\widehat{r}_{i j 1}^{(3)}\right|+\left|\widehat{r}_{i j 2}^{(1)}-\widehat{r}_{i j 2}^{(q 3)}\right|+\left|\widehat{r}_{i j 3}^{(1)}-\widehat{r}_{i j 3}^{(3)}\right|}{3}\right)=0.8125, \\
& S\left(\widehat{R}_{3}, \widehat{R}_{2}\right)=\frac{1}{6 \times 5} \sum_{i=1}^{6} \sum_{j=1}^{5}\left(1-\frac{\left|\widehat{r}_{i j 1}^{(3)}-\widehat{r}_{i j 1}^{(2)}\right|+\left|\widehat{r}_{i j 2}^{(3)}-\widehat{r}_{i j 2}^{(q 2)}\right|+\left|\widehat{r}_{i j 3}^{(3)}-\widehat{r}_{i j 3}^{(2)}\right|}{3}\right)=0.8200 .
\end{aligned}
$$

Step 2.2. Calculate the average degree of agreement of expert as follows:

$$
\begin{aligned}
& A\left(E_{1}\right)=\frac{1}{3-1} \sum_{j=2, j \neq i}^{3} S\left(\widehat{R}_{1}, \widehat{R}_{j}\right)=0.813, \\
& A\left(E_{2}\right)=\frac{1}{3-1} \sum_{j=1, j \neq i}^{3} S\left(\widehat{R}_{2}, \widehat{R}_{j}\right)=0.816, \\
& A\left(E_{3}\right)=\frac{1}{3-1} \sum_{j=1, j \neq i}^{3} S\left(\widehat{R}_{3}, \widehat{R}_{j}\right)=0.816 .
\end{aligned}
$$


Table 5: The functional requirements of criteria.

\begin{tabular}{lllll}
\hline$C_{1}$ & $C_{2}$ & $C_{3}$ & $C_{4}$ & $C_{5}$ \\
\hline $\mathrm{H}$ & $\mathrm{H}$ & $\mathrm{M}$ & $\mathrm{H}$ & $\mathrm{M}$ \\
\hline
\end{tabular}

Table 6: The transformed evaluation information of KMSs given by the first respondent.

\begin{tabular}{cccccc}
\hline & $C_{1}$ & $C_{2}$ & $C_{3}$ & $C_{4}$ & $C_{5}$ \\
\hline$A_{1}$ & $(0.5,0.65,0.8)$ & $(0.5,0.65,0.8)$ & $(0.5,0.7,0.8)$ & $(0.65,0.8,0.95)$ & $(0.5,0.65,0.8)$ \\
$A_{2}$ & $(0.65,0.8,0.95)$ & $(0.65,0.8,0.95)$ & $(0.65,0.8,0.95)$ & $(0.2,0.4,0.5)$ & $(0.65,0.8,0.95)$ \\
$A_{3}$ & $(0.35,0.5,0.65)$ & $(0.35,0.5,0.65)$ & $(0.5,0.7,0.8)$ & $(0.5,0.7,0.8)$ & $(0.5,0.65,0.8)$ \\
$A_{4}$ & $(0.5,0.65,0.8)$ & $(0.5,0.65,0.8)$ & $(0.35,1,0.65)$ & $(0.35,0.5,0.65)$ & $(0.5,0.65,0.8)$ \\
$A_{5}$ & $(0.35,0.5,0.65)$ & $(0.65,0.8,0.95)$ & $(0.35,0.5,0.65)$ & $(0.2,0.4,0.5)$ & $(0.65,0.8,0.95)$ \\
$A_{6}$ & $(0.35,0.5,0.65)$ & $(0.5,0.65,0.8)$ & $(0.2,0.4,0.5)$ & $(0.65,0.8,0.95)$ & $(0.2,0.35,0.5)$ \\
\hline
\end{tabular}

Step 2.3. Calculate the relative degree of agreement of expert as follows:

$$
\begin{aligned}
& R A\left(E_{1}\right)=\frac{A\left(E_{1}\right)}{\sum_{i=1}^{n} A\left(E_{i}\right)}=0.332, \\
& R A\left(E_{2}\right)=\frac{A\left(E_{2}\right)}{\sum_{i=1}^{n} A\left(E_{i}\right)}=0.334, \\
& R A\left(E_{3}\right)=\frac{A\left(E_{3}\right)}{\sum_{i=1}^{n} A\left(E_{i}\right)}=0.334 .
\end{aligned}
$$

Step 2.4. Calculate the consensus degree coefficient as follows:

$$
\begin{aligned}
& C\left(E_{1}\right)=\frac{0.5}{0.5+0.5} * w_{1}+\frac{0.5}{0.5+0.5} * R A\left(E_{1}\right)=0.316 \\
& C\left(E_{2}\right)=\frac{0.5}{0.5+0.5} * w_{2}+\frac{0.5}{0.5+0.5} * R A\left(E_{2}\right)=0.317 \\
& C\left(E_{3}\right)=\frac{0.5}{0.5+0.5} * w_{3}+\frac{0.5}{0.5+0.5} * R A\left(E_{31}\right)=0.367 .
\end{aligned}
$$

Step 2.5. Aggregate the fuzzy opinions. The aggregated results are obtained, and they are presented in Table 10.

From the table we see that the value of alternative $A_{5}$ on criterion $C_{4}$ is beyond the scope of the function requirement. Therefore $A_{5}$ is dropped from the set of available alternatives. 
Table 7: The transformed evaluation information of KMSs given by the second respondent.

\begin{tabular}{lccccc}
\hline & $C_{1}$ & $C_{2}$ & $C_{3}$ & $C_{4}$ & $C_{5}$ \\
\hline$A_{1}$ & $(0.5,0.65,0.8)$ & $(0.35,0.5,0.65)$ & $(0.65,0.8,0.95)$ & $(0.2,0.4,0.5)$ & $(0.5,0.65,0.8)$ \\
$A_{2}$ & $(0.65,0.8,0.95)$ & $(0.65,0.8,0.95)$ & $(0.35,0.5,0.65)$ & $(0.05,0.2,0.35)$ & $(0.2,0.35,0.5)$ \\
$A_{3}$ & $(0.5,0.65,0.8)$ & $(0.35,0.5,0.65)$ & $(0.2,0.4,0.5)$ & $(0.65,0.8,0.95)$ & $(0.5,0.65,0.8)$ \\
$A_{4}$ & $(0.5,0.65,0.8)$ & $(0.5,0.65,0.8)$ & $(0.5,0.7,0.8)$ & $(0.35,0.5,0.65)$ & $(0.35,0.5,0.65)$ \\
$A_{5}$ & $(0.35,0.5,0.65)$ & $(0.65,0.8,0.95)$ & $(0.35,0.5,0.65)$ & $(0.2,0.4,0.5)$ & $(0.5,0.65,0.8)$ \\
$A_{6}$ & $(0.35,0.5,0.65)$ & $(0.35,0.5,0.65)$ & $(0.65,0.8,0.95)$ & $(0.35,0.5,0.65)$ & $(0.35,0.5,0.65)$ \\
\hline
\end{tabular}

Table 8: The transformed evaluation information of KMSs given by the third respondent.

\begin{tabular}{cccccc}
\hline & $C_{1}$ & $C_{2}$ & $C_{3}$ & $C_{4}$ & $C_{5}$ \\
\hline$A_{1}$ & $(0.35,0.5,0.65)$ & $(0.5,0.65,0.8)$ & $(0.65,0.8,0.95)$ & $(0.05,0.2,0.35)$ & $(0.5,0.65,0.8)$ \\
$A_{2}$ & $(0.5,0.65,0.8)$ & $(0.65,0.8,0.95)$ & $(0.35,0.5,0.65)$ & $(0.35,0.5,0.65)$ & $(0.5,0.65,0.8)$ \\
$A_{3}$ & $(0.35,0.5,0.65)$ & $(0.35,0.5,0.65)$ & $(0.65,0.8,0.95)$ & $(0.65,0.8,0.95)$ & $(0.35,0.5,0.65)$ \\
$A_{4}$ & $(0.5,0.65,0.8)$ & $(0.5,0.65,0.8)$ & $(0.35,0.5,0.65)$ & $(0.35,0.5,0.65)$ & $(0.35,0.5,0.65)$ \\
$A_{5}$ & $(0.5,0.65,0.8)$ & $(0.65,0.8,0.95)$ & $(0.65,0.8,0.95)$ & $(0.2,0.4,0.5)$ & $(0.35,0.5,0.65)$ \\
$A_{6}$ & $(0.35,0.5,0.65)$ & $(0.35,0.5,0.65)$ & $(0.2,0.4,0.5)$ & $(0.5,0.7,0.8)$ & $(0.65,0.8,0.95)$ \\
\hline
\end{tabular}

Step 3. Calculate the information content. The calculation of information content $I_{11}$ of alternative $A_{1}$ on criterion $C_{1}$ is provided as an illustration:

$$
\begin{aligned}
I_{11} & =\log _{2} \frac{\text { System Area of } A_{11}}{\text { Common Area of } A_{11} \text { and } F R_{1}} \\
& =\log _{2} \frac{\text { Area of triangle }(0.445,0.595,0.745)}{\text { Intersection Area of triangle }(0.445,0.595,0.745) \text { and triangle }(0.5,0.65,0.8)} \\
& =\log _{2} \frac{0.15}{0.100}=0.585,
\end{aligned}
$$

where $F R_{1}$ is the function requirement of criterion $C_{1}$ and $A_{11}$ is the evaluation information of the alternative $A_{1}$ on criterion $C_{1}$.

The calculating results of all the information content are shown in Table 11.

Step 4. Calculation of the weighted information content. First, we utilize the model (M) to establish the following single-objective nonlinear programming model:

$$
\min \quad d(w)=4.889 \times \frac{1}{w_{1}}+5.705 \times \frac{1}{w_{2}}+8.306 \times \frac{1}{w_{3}}+17.416 \times \frac{1}{w_{4}}+5.475 \times \frac{1}{w_{5}}
$$

subject to $w \in H$.

By solving this model, we get the weight vector of criteria as follows:

$$
w=(0.180,0.210,0.190,0.30,0.120) .
$$


Table 9: The transformed functional requirements of the criteria.

\begin{tabular}{lcccc}
\hline$C_{1}$ & $C_{2}$ & $C_{3}$ & $C_{4}$ & $C_{5}$ \\
\hline$(0.5,0.65,0.8)$ & $(0.5,0.65,0.8)$ & $(0.35,0.5,0.65)$ & $(0.5,0.7,0.8)$ & $(0.35,0.5,0.65)$ \\
\hline
\end{tabular}

Table 10: The aggregated evaluation information of the alternatives.

\begin{tabular}{lccc}
\hline & $C_{1}$ & $C_{2}$ & $C_{3}$ \\
\hline$A_{1}$ & $(0.445,0.595,0.745)$ & $(0.452,0.602,0.752)$ & $(0.603,0.753,0.903)$ \\
$A_{2}$ & $(0.595,0.745,0.895)$ & $(0.650,0.800,0.950)$ & $(0.445,0.595,0.745)$ \\
$A_{3}$ & $(0.398,0.548,0.698)$ & $(0.350,0.500,0.650)$ & $(0.460,0.610,0.760)$ \\
$A_{4}$ & $(0.500,0.650,0.800)$ & $(0.500,0.650,0.800)$ & $(0.398,0.548,0.698)$ \\
$A_{5}$ & $(0.405,0.555,0.705)$ & $(0.650,0.800,0.950)$ & \\
$A_{6}$ & $(0.350,0.500,0.650)$ & $(0.397,0.547,0.697)$ & \\
\hline & $C_{4}$ & $C_{5}$ & \\
\hline$A_{1}$ & $(0.287,0.437,0.587)$ & $(0.500,0.650,0.800)$ & \\
$A_{2}$ & $(0.208,0.358,0.508)$ & $(0.452,0.602,0.03,0.643)$ \\
$A_{3}$ & $(0.603,0.753,0.903)$ & $(0.445,0.595,0.745)$ & \\
$A_{4}$ & $(0.350,0.500,0.650)$ & $(0.397,0.547,0.697)$ & \\
$A_{5}$ & $(0.200,0.350,0.500)$ & $(0.492,0.642,0.792)$ & \\
$A_{6}$ & $(0.500,0.650,0.800)$ & $(0.413,0.563,0.713)$ & \\
\hline
\end{tabular}

By utilizing the weight vector $w$ and by (3.7) and (3.8), we can calculate the weighted information content and total weighted information content.

In the following the calculation of alternative $A_{1}$ is provided as an illustration:

$$
\begin{aligned}
I_{1}^{w} & =\sum_{j=1}^{5} I_{1 j}^{w} \\
& =\sum_{j=1}^{5} I_{1 j} \times \frac{1}{w_{j}} \\
& =0.585 \times \frac{1}{0.180}+0.498 \times \frac{1}{0.210}+5.323 \times \frac{1}{0.190}+3.564 \times \frac{1}{0.30}+2.000 \times \frac{1}{0.120} \\
& =62.18 .
\end{aligned}
$$

The calculated results of all the alternatives are shown in Table 12.

Step 5. Select the best alternative. Rank the alternatives in ascending order of the total weighted information content. The final ranking of the alternatives is

$$
A_{4}>A_{6}>A_{3}>A_{2}>A_{1} \text {. }
$$

From the final ranking, clearly, we see that $A_{4}$ is the fittest knowledge management system, followed by $A_{6}>A_{3}>A_{2}$, while $A_{1}$ is considered as the least fit. 
Table 11: The information content of the alternatives.

\begin{tabular}{lccccc}
\hline & $C_{1}$ & $C_{2}$ & $C_{3}$ & $C_{4}$ & $C_{5}$ \\
\hline$A_{1}$ & 0.585 & 0.498 & 5.323 & 3.564 & 2.000 \\
$A_{2}$ & 1.098 & 2.000 & 1.097 & 10.644 & 1.204 \\
$A_{3}$ & 1.206 & 2.000 & 1.317 & 1.207 & 1.098 \\
$A_{4}$ & 0.000 & 0.000 & 0.498 & 2.000 & 0.496 \\
$A_{6}$ & 2.000 & 1.207 & 0.072 & 0.001 & 0.676 \\
\hline
\end{tabular}

Table 12: The weighted information content of the alternatives.

\begin{tabular}{ccccccc}
\hline & $C_{1}$ & $C_{2}$ & $C_{3}$ & $C_{4}$ & $C_{5}$ & Total \\
\hline$A_{1}$ & 3.249 & 2.370 & 28.01 & 11.880 & 11.88 & 62.180 \\
$A_{2}$ & 6.101 & 9.524 & 5.771 & 35.480 & 35.48 & 66.908 \\
$A_{3}$ & 6.698 & 9.524 & 6.933 & 4.024 & 9.151 & 36.331 \\
$A_{4}$ & 0.000 & 0.000 & 2.620 & 6.667 & 4.137 & 13.424 \\
$A_{6}$ & 11.111 & 5.749 & 0.379 & 0.004 & 5.633 & 22.875 \\
\hline
\end{tabular}

The final ranking of the alternatives is the trade-off of the performances on the criteria. For example, the value of $A_{6}$ on $C_{4}$ is the closest to the design requirement. However, the values of $A_{6}$ on the other criteria are far from the design requirements. On the contrary, all the values of alternative $A_{4}$ on the criteria are not too far from the design requirements and hence the overall performance is better.

\section{Conclusions}

In this paper, we make the extension of axiomatic design method for fuzzy linguistic multiple criteria group decision making with incomplete weight information. With respect to multiple criteria group decision making (MCDM) based on axiomatic design with incomplete weight information under fuzzy linguistic environment, the new method is proposed. In order to get the weight vector of the criteria, the nonlinear optimization model based on the basic ideal of axiomatic design is constructed. It is based on the main principle of fuzzy axiomatic design that the optimal alternative should have the least weighted information content. Then, the total weighted information content of each alternative is derived by summing weighted information content for each criterion. The alternatives are ranked in descending order of total weighted information content. The availability of the proposed method is validated by the numerical example.

The major advantages of the proposed method are as follows.

(i) The user can give linguistic opinions in the application of axiomatic design for MCDM problems because of the extension of axiomatic design under fuzzy linguistic environment.

(ii) In case of incomplete weight information, the axiomatic design still works well because of the extension of axiomatic design method with incomplete weight information.

(iii) The method allows for the selection of not only the best alternative within a set of criteria but also the most appropriate alternative. It is an extension of traditional MCDM methods which can only deal with extreme numbers. 
Moreover, the numerical example can be a reference for the knowledge management system evaluation and selection.

In the future research of axiomatic design, the weights of the criteria in the other form rather than numeric intervals will be considered.

\section{Acknowledgments}

The research is supported by the National Natural Science Foundation of China under Grant no. 71101153 and the research funds provided to new recruitments of China University of Petroleum, Beijing (QD-2010-06).

\section{References}

[1] C. Kahraman, S. Çevik, N. Y. Ates, and M. Gülbay, “Fuzzy multi-criteria evaluation of industrial robotic systems," Computers and Industrial Engineering, vol. 52, no. 4, pp. 414-433, 2007.

[2] E. E. Karsak, “Distance-based fuzzy MCDM approach for evaluating flexible manufacturing system alternatives," International Journal of Production Research, vol. 40, no. 13, pp. 3167-3181, 2002.

[3] B. L. Foote, A. Ravindran, and S. Lashine, "Production planning \& scheduling. Computational feasibility of multi-criteria models of production, planning and scheduling," Computers and Industrial Engineering, vol. 15, no. 1-4, pp. 129-138, 1988.

[4] H. K. Chiou and G. H. Tzeng, "Fuzzy multiple-criteria decision-making approach for industrial green engineering," Environmental Management, vol. 30, no. 6, pp. 816-830, 2002.

[5] R. Kodali and G. Anand, "Application of analytic network process for the design of flexible manufacturing systems," Global Journal of Flexible Systems Management, vol. 11, no. 1-2, pp. 39-54, 2010.

[6] T. C. Hsia, H. T. Chen, and W. H. Chen, "Measuring the readability performance (RP) of aircraft maintenance technical orders by fuzzy MCDM method and RP index," Quality and Quantity, vol. 42, no. 6, pp. 795-807, 2008.

[7] M. A. E. Nik, N. Khademolhosseini, M. H. Abbaspour-Fard, A. Mahdinia, and K. Alami-Saied, "Optimum utilisation of low-capacity combine harvesters in high-yielding wheat farms using multicriteria decision making," Biosystems Engineering, vol. 103, no. 3, pp. 382-388, 2009.

[8] M. Li, L. Liu, and C. B. Li, "An approach to expert recommendation based on fuzzy linguistic method and fuzzy text classification in knowledge management systems," Expert Systems with Applications, vol. 38, no. 7, pp. 8586-8596, 2011.

[9] G. Büyüközkan and D. Ruan, "Evaluation of software development projects using a fuzzy multicriteria decision approach," Mathematics and Computers in Simulation, vol. 77, no. 5-6, pp. 464-475, 2008.

[10] R. A. Ribeiro, A. M. Moreira, P. van den Broek, and A. Pimentel, "Hybrid assessment method for software engineering decisions," Decision Support Systems, vol. 51, no. 1, pp. 208-219, 2011.

[11] H. K. Jain, M. R. Tanniru, and B. Fazlollahi, "MCDM approach for generating and evaluating alternatives in requirement analysis," Information Systems Research, vol. 2, no. 3, pp. 223-239, 1991.

[12] M. Pirdashti, A. Ghadi, M. Mohammadi, and G. Shojatalab, "Multi-criteria decision-making selection model with application to chemical engineering management decisions," Proceedings of World Academy of Science, Engineering and Technology, vol. 37, pp. 54-59, 2009.

[13] X. P. Jia, F. Y. Han, and X. S. Tan, "Integrated environmental performance assessment of chemical processes," Computers and Chemical Engineering, vol. 29, no. 1, pp. 243-247, 2004.

[14] T. Y. Hsieh, S. T. Lu, and G. H. Tzeng, "Fuzzy MCDM approach for planning and design tenders selection in public office buildings," International Journal of Project Management, vol. 22, no. 7, pp. 573$584,2004$.

[15] J. Ma, J. Lu, and G. Zhang, "Decider: A fuzzy multi-criteria group decision support system," Knowledge-Based Systems, vol. 23, no. 1, pp. 23-31, 2010. 
[16] L. A. Zadeh, "Fuzzy sets," Information and Computation, vol. 8, no. 3, pp. 338-353, 1965.

[17] F. Herrera and L. Martínez, "A 2-tuple fuzzy linguistic representation model for computing with words," IEEE Transactions on Fuzzy Systems, vol. 8, no. 6, pp. 746-752, 2000.

[18] T.-C. Chu and Y. Lin, "An extension to fuzzy MCDM," Computers E Mathematics with Applications, vol. 57, no. 3, pp. 445-454, 2009.

[19] Y. Deng and F. T. S. Chan, "A new fuzzy dempster MCDM method and its application in supplier selection," Expert Systems with Applications, vol. 38, no. 8, pp. 9854-9861, 2011.

[20] J. F. Ding and G. S. Liang, "Using fuzzy MCDM to select partners of strategic alliances for liner shipping," Information Sciences, vol. 173, no. 1-3, pp. 197-225, 2005.

[21] C. T. Chen, C. T. Lin, and S. F. Huang, "A fuzzy approach for supplier evaluation and selection in supply chain management," International Journal of Production Economics, vol. 102, no. 2, pp. 289-301, 2006.

[22] C. Carlsson, "Tackling an MCDM-problem with the help of some results from fuzzy set theory," European Journal of Operational Research, vol. 10, no. 3, pp. 270-281, 1982.

[23] C. C.Sun, "A performance evaluation model by integrating fuzzy AHP and fuzzy TOPSIS methods," Expert Systems with Applications, vol. 37, no. 12, pp. 7745-7754, 2010.

[24] C. C. Sun, G. T. R. Lin, and G. H. Tzeng, "The evaluation of cluster policy by fuzzy MCDM: Empirical evidence from HsinChu Science Park," Expert Systems with Applications, vol. 36, no. 9, pp. 11895-11906, 2009.

[25] C.-C. Chou, "A fuzzy MCDM method for solving marine transshipment container port selection problems," Applied Mathematics and Computation, vol. 186, no. 1, pp. 435-444, 2007.

[26] C. H. Cheng, "Evaluating weapon systems using ranking fuzzy numbers," Fuzzy Sets and Systems, vol. 107, no. 1, pp. 25-35, 1999.

[27] C.-C. Hon, Y.-Y. Guh, K.-M. Wang, and E. S. Lee, “Fuzzy multiple attributes and multiple hierarchical decision making," Computers E Mathematics with Applications, vol. 32, no. 12, pp. 109-119, 1996.

[28] C. T. Chen, "Extensions of the TOPSIS for group decision-making under fuzzy environment," Fuzzy Sets and Systems, vol. 114, no. 1, pp. 1-9, 2000.

[29] S. Opricovic, Multicriteria Optimization of Civil Engineering Systems, Faculty of Civil Engineering, Belgrade, Serbia, 1998.

[30] S. Opricovic, "Fuzzy VIKOR with an application to water resources planning," Expert Systems with Applications, vol. 38, no. 10, pp. 12983-12990, 2011.

[31] D. Y. Chang, "Applications of the extent analysis method on fuzzy AHP," European Journal of Operational Research, vol. 95, no. 3, pp. 649-655, 1996.

[32] M. Goumas and V. Lygerou, "Extension of the PROMETHEE method for decision making in fuzzy environment: ranking of alternative energy exploitation projects," European Journal of Operational Research, vol. 123, no. 3, pp. 606-613, 2000.

[33] W. H. Chen, M. S. Tsai, and H. L. Kuo, “Distribution system restoration using the hybrid fuzzy-grey method," IEEE Transactions on Power Systems, vol. 20, no. 1, pp. 199-205, 2005.

[34] N. P. Suh and S. Sekimoto, "Design of thinking design machine," Annals of the CIRP, vol. 39, no. 1, pp. 145-148, 1990.

[35] N. P. Suh, Axiomatic Design: Advance and Applications, Oxford University Press, New York, NY, USA, 2001.

[36] B. Babic, "Axiomatic design of flexible manufacturing systems," International Journal of Production Research, vol. 37, no. 5, pp. 1159-1173, 1999.

[37] O. Kulak, "A decision support system for fuzzy multi-attribute selection of material handling equipments," Expert Systems with Applications, vol. 29, no. 2, pp. 310-319, 2005.

[38] O. Kulak and C. Kahraman, "Fuzzy multi-attribute selection among transportation companies using axiomatic design and analytic hierarchy process," Information Sciences, vol. 170, no. 2-4, pp. 191-210, 2005.

[39] O. Kulak and C. Kahraman, "Multi-attribute comparison of advanced manufacturing systems using fuzzy versus crisp axiomatic design approach," International Journal of Production Economics, vol. 95, no. 3, pp. 415-424, 2005.

[40] O. Kulak, M. B. Durmuşoğlu, and C. Kahraman, “Fuzzy multi-attribute equipment selection based on information axiom," Journal of Materials Processing Technology, vol. 169, no. 3, pp. 337-345, 2005. 
[41] A. M. Gonçalves-Coelho and A. J. F. Mourão, "Axiomatic design as support for decision-making in a design for manufacturing context: a case study," International Journal of Production Economics, vol. 109, no. 1-2, pp. 81-89, 2007.

[42] M. Celik, C. Kahraman, S. Cebi, and I. D. Er, "Fuzzy axiomatic design-based performance evaluation model for docking facilities in shipbuilding industry: the case of Turkish shipyards," Expert Systems with Applications, vol. 36, no. 1, pp. 599-615, 2009.

[43] Y. Deng, J. Xiong, and P. Fu, "Airline safety evaluation based on fuzzy TOPSIS," Lecture Notes in Computer Science, vol. 4430, pp. 282-287, 2007.

[44] M. Dağdeviren, S. Yavuz, and N. Kılınç, "Weapon selection using the AHP and TOPSIS methods under fuzzy environment," Expert Systems with Applications, vol. 36, no. 4, pp. 8143-8151, 2009.

[45] S. M. Chen, "Aggregating fuzzy opinions in the group decision-making environment," Cybernetics and Systems, vol. 29, no. 4, pp. 363-376, 1998.

[46] S. H. Kim and B. S. Ahn, "Interactive group decision making procedure under incomplete information," European Journal of Operational Research, vol. 116, no. 3, pp. 498-507, 1999.

[47] S. H. Kim, S. H. Choi, and J. K. Kim, "Interactive procedure for multiple attribute group decision making with incomplete information: range-based approach," European Journal of Operational Research, vol. 118, no. 1, pp. 139-152, 1999.

[48] K. S. Park and S. H. Kim, "Tools for interactive multiattribute decisionmaking with incompletely identified information," European Journal of Operational Research, vol. 98, no. 1, pp. 111-123, 1997.

[49] K. S. Park, S. H. Kim, and W. C. Yoon, "Establishing strict dominance between alternatives with special type of incomplete information," European Journal of Operational Research, vol. 96, no. 2, pp. 398-406, 1997.

[50] M. Li, L. Liu, L. Yin, and Y. Zhu, "A process mining based approach to knowledge maintenance," Information Systems Frontiers, vol. 13, no. 3, pp. 371-380, 2010. 


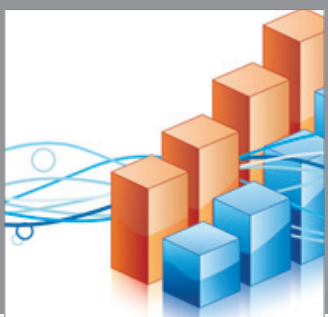

Advances in

Operations Research

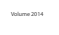

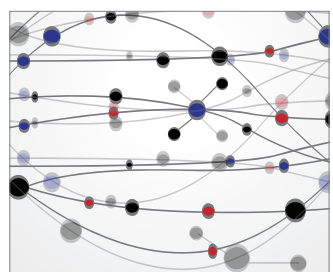

\section{The Scientific} World Journal
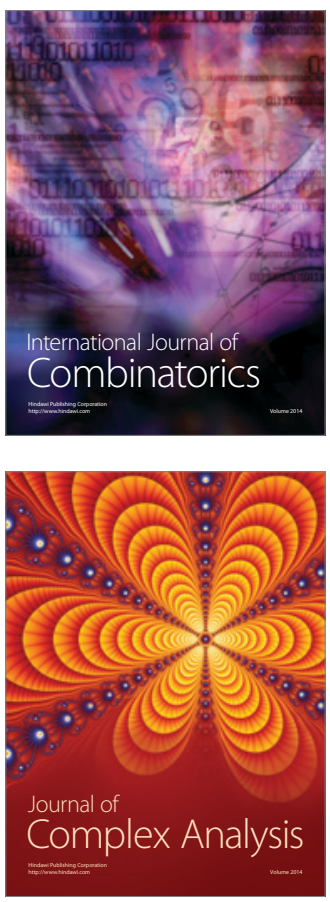

International Journal of

Mathematics and

Mathematical

Sciences
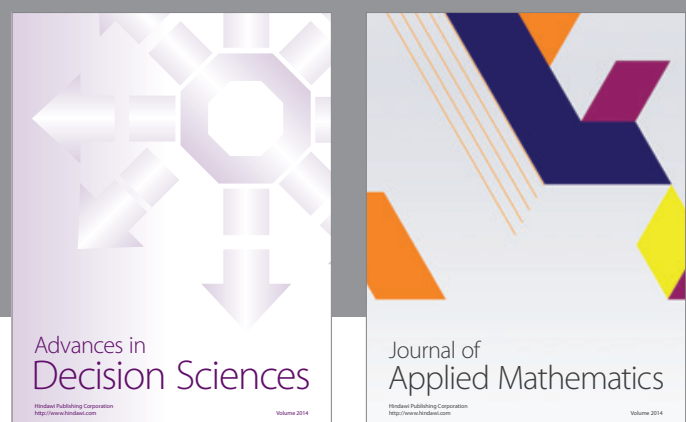

Journal of

Applied Mathematics
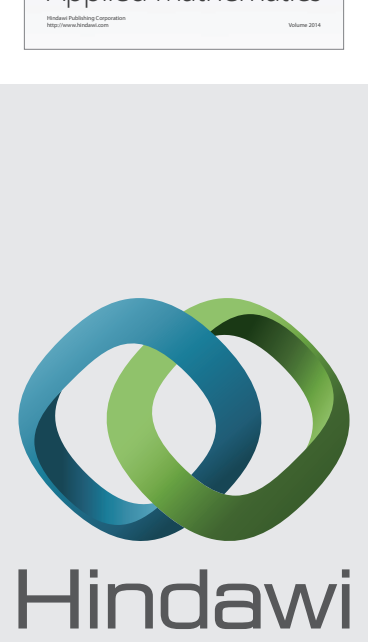

Submit your manuscripts at http://www.hindawi.com
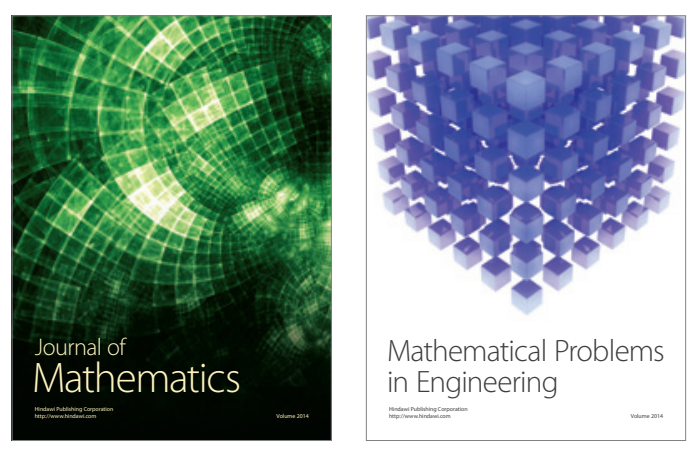

Mathematical Problems in Engineering
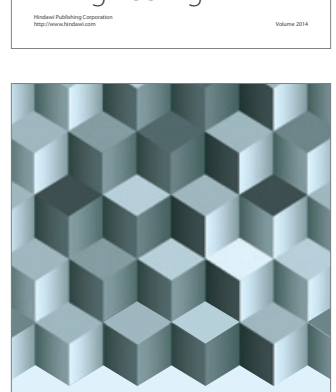

Journal of

Function Spaces
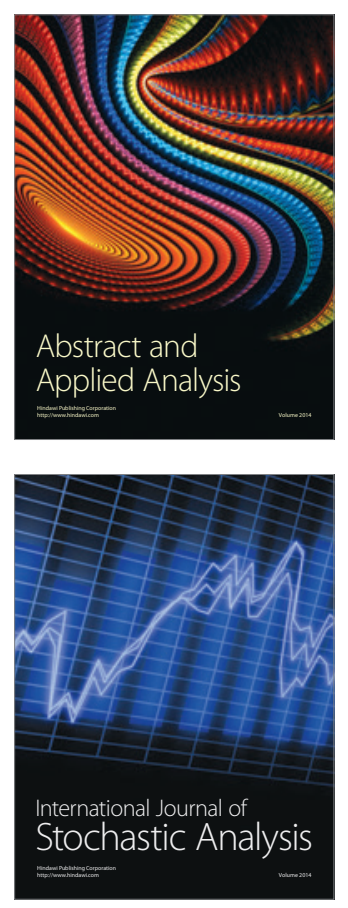

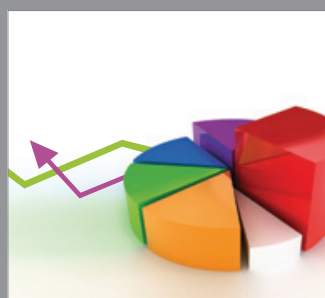

ournal of

Probability and Statistics

Promensencen
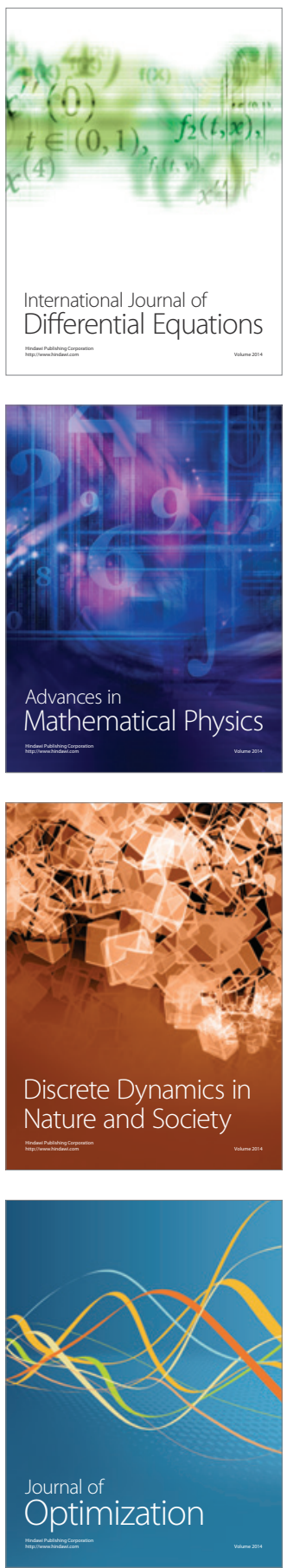